\section{EMBRYRIDDLE \\ Aeronautical University}

SCHOLARLY COMMONS
International Journal of Aviation, Aeronautics, and Aerospace

7-1-2017

\title{
A Conceptual Model for a Universal Severity of Emergency Report (USER): An Example in Aviation
}

\author{
Scott R. Winter \\ Embry-Riddle Aeronautical University, scott.winter@mac.com \\ Stephen Rice \\ Embry-Riddle Aeronautical University, rices15@erau.edu \\ Mattie Milner \\ Embry-Riddle Aeronautical University, milnerm1@my.erau.edu \\ William B. Coyne \\ Embry-Riddle Aeronautical University, coynea7e@erau.edu \\ Martin Lauth \\ Embry-Riddle Aeronautical University, Martin.Lauth@erau.edu \\ Clyde Rinkinen \\ Embry-Riddle Aeronautical University, Clyde.Rinkinen@erau.edu
}

Follow this and additional works at: https://commons.erau.edu/ijaaa

Part of the Other Psychology Commons

\section{Scholarly Commons Citation}

Winter, S. R., Rice, S., Milner, M., Coyne, W. B., Lauth, M., \& Rinkinen, C. (2017). A Conceptual Model for a Universal Severity of Emergency Report (USER): An Example in Aviation. International Journal of Aviation, Aeronautics, and Aerospace, 4(3). https://doi.org/10.15394/ijaaa.2017.1173

This Literature Review is brought to you for free and open access by the Journals at Scholarly Commons. It has been accepted for inclusion in International Journal of Aviation, Aeronautics, and Aerospace by an authorized administrator of Scholarly Commons. For more information, please contact commons@erau.edu. 
A short example is provided to assist with the introduction and need of this new communication model. The quiet of the night was broken by a mayday call that came through the controller's headset on the emergency guard frequency. A VFR (visual flight rules) pilot practicing night landings at a local non-towered airport had become disorientated in deteriorating weather conditions, and the pilot was unable to maintain visual conditions:

PILOT: MAYDAY, MAYDAY, MAYDAY

ATC: Aircraft calling on guard, go ahead

PILOT: I have flown into the clouds, and I don't know where I am, N1234.

ATC: Roger, N1234, I understand you're declaring an emergency, say your intentions.

PILOT: I need vectors to get out of the clouds.

The controller asked the pilot several questions such as souls onboard and fuel remaining:

ATC: N1234, say souls onboard and fuel remaining.

PILOT: 1 soul onboard and three hours.

To help the pilot, the controllers assigned a transponder code to provide vectors to the nearest airport:

ATC: N1234 squawk, 4273

PILOT: 4273

The controller also attempts to identify whether the pilot is trained to fly in the clouds:

ATC: N1234, radar contact, are you instrument rated and equipped for IFR flight?

PILOT: Negative, I've never flown in the clouds before.

What the controller lacks in the scenario so far is any information on how severe the pilot perceives this emergency to be, their capabilities to handle it (regardless of their qualifications) and if they are free to communicate. Note that pilots are trained to aviate, navigate, and communicate, in that order. So, communication is their last priority in an emergency.

ATC: N1234, I can provide you with radar vectors to the nearest VFR airport, can you fly heading 280 ? 


\section{PILOT: N1234, I am feeling disorientated.}

The controller sees the aircraft on radar enter a descending, right-hand spiral and disappear from their radar screen. The pilot of the aircraft lost control of the aircraft in instrument meteorological conditions and was killed upon impact with the ground. The authors pose that this is a well-handled event by the controller. In receiving the message, the controller had to work diligently to obtain information to try and assist the pilot in safely exiting the conditions, but the controller was provided with very little information or context from which to process the severity of the emergency, the capabilities of the pilot, and if the pilot could communicate freely with the controller.

Sadly, in general aviation, this is not a unique scenario (NTSB, 1989; O'Hare \& Smitheram, 1995; Wiegmann \& Goh, 2000). According to the Aircraft Owner's and Pilot's Association (AOPA), over two-thirds of VFR into IMC (instrument meteorological conditions) accidents result in fatalities (2016). This paper will propose a new type of emergency communication model, the Universal Severity of Emergency Report (USER). The purpose of this report is to enhance the amount of information that is conveyed during urgent and time-sensitive scenarios. After introducing the concept, the preceding scenario will be replicated using the USER rating.

\section{Literature Review}

\section{Background on Communicating}

For communication to occur, there need to be two parties: a sender and a receiver. The sender creates and transmits the message, which is then received by the second individual. This individual must process the received information and construct it into a meaningful representation, with or without other information for context (Cushing, 1994). In the case of aviation, transmissions between a pilot and air traffic control are accomplished via radio, so there are no additional cues available between the sender and the receiver, such as facial expressions, to help convey the context of the message (Knapp, Hall \& Horgan, 2012; Russell \& Fernandez-Dols, 1997). Additionally, distortion of voices can sometimes occur via radio voice communications, which could further lead to interruptions in the interpretation of the message. This can be particularly challenging when the two people communicating come from different cultures or linguistic backgrounds (MacBurnie, 2004). 
The receiver may use the secondary information to infer context. For example, the phrase "I need help" could be said in some different tones or speeds that could be processed differently by the receiver (Drury \& Ma, 2002). In an aviation context, this could create a disconnect because pilots are taught to remain calm in stressful situations. Therefore, if they transmit a mayday, sounding calm and collected, that could be misinterpreted by the air traffic controller as a situation that is not that severe, when in fact, the severity level could be very high. USER creates a reporting model where the gravity of the situation, capabilities of the pilot, and communication ability of the pilot can quickly be conveyed to the receiver of the message. The system quickly provides three key pieces of information so that the receiver of the message is made aware of the severity, capabilities, and communication needs of the individual sending the message.

Prior research (Kanki \& Palmer, 1993) discusses how essential communication between pilots and air traffic controllers can be to the safety of flight. Examples such as the Avianca Airlines Flight 52 accident in New York in 1990 highlight how communications can break down in emergency situations. In this accident, a major focal point was confusion between air traffic controllers and the pilots when the pilots stated they need "priority" instead of using the word "emergency." The pilots felt like they had conveyed the urgency of their situation, while air traffic controllers did not understand the level of urgency. In a review of National Aeronautics and Space Administration's (NASA) Aviation Safety Reporting System, Connell (1996) found that approximately $70 \%$ of some 28,000 reports cited problems with the "transfer of information in the aviation system" (p. 20).

\section{Purpose for Developing the USER System}

In states of emergency, communication needs to be concise and explicit. However, there is a chance of disinformation or failure in comprehension when one just declares an emergency. Often, the recipient of the emergency call wants to respond by asking for more information. Typically, there are three areas that need further information. First is the severity of the emergency. Emergencies can vary from ones that are easily handled by the operators to those that may be on the verge of losing control of the situation.

Second, what is the capability of the individual or operator that has incurred the emergency situation? This can vary based on each person and their experience level. What is important to highlight here is that the USER model does not rely on a standardized assessment of capabilities but rather the capabilities of each person. The main component of capability is how much help the person 
requires. This gives others, which may be able to help, full knowledge of what the other person is seeking. Furthermore, it removes the need for the helper to identify the skill level of the other individual. Whether they are a novice or an expert, if they are operating at full capacity, and need help, that is the important piece of information to be communicated at that time.

Finally, the last component of USER is communication. Communication conveys whether the individual or operator is willing and able to talk. In some situations, the individual may need to complete checklists or respond in an urgent fashion where lengthy communication is not feasible, but in other cases, they may be able/need/want to communicate while also addressing the situation.

\section{Introducing the Universal Severity of Emergency Report (USER) Severity}

In any given emergency, the severity of the event can have various rankings. With the USER model, there are three levels of severity, and they are defined as follows:

1) Minor

2) Moderate

3) Severe

We note here that the severity rating is always given by the sender, and does not necessarily reflect a universal rating. For example, a novice might perceive a situation deemed minor by an experienced pilot as severe. Thus, solely the pilot makes the determination of the code here.

\section{Capabilities}

The capabilities of the operator are the second component of USER. Capabilities are represented using colors, and they are defined as follows:

\begin{tabular}{|ll}
\hline White: & I do not need any help \\
\hline Yellow: & I may need help \\
\hline Red: & I need help
\end{tabular}

White is a traditional color for "advisory." We wish to avoid the use of green as it has such strong connotations in society (e.g. "go" or "all clear"). This could confuse a receiver if the pilot says, "3, green, standby". The three clearly states a serious emergency, while the green seems to imply that all is well. White 
means that something may be wrong, but "I do not need any help." Yellow is the universal color for caution, and red is the universal color for warning or danger.

The capabilities of operators during emergencies are subjective. A novice operator may be overwhelmed in a scenario that would be routine for an expert. However, experience level is irrelevant when using the USER model because what is important is that regardless of skill level, the capabilities of the individual are conveyed to the other parties. This also prevents the receiver of the message from self-determining the other individual's experience level and judging their capability to handle the emergency, which could lead to ambiguous results.

\section{Communication}

There are two options for the communication part of USER which relate to the feedback that the sender is requesting from the receiver of the message:

Communicate: Able to talk

Standby: Wait, I'm overloaded, and I will get back to you

During this time, the pilot can also convey any additional information to the air traffic controller, such as the nature of the emergency or the resources they are requesting for help. If the pilot states "communicate," it also indicates they can respond to queries from air traffic control.

\section{Use of the Scale}

In emergency situations, the level of the emergency can vary. For example, in the case of an engine failure in a turbine engine commercial aircraft, clearly, an emergency would be declared by the pilots to obtain priority handling and expedite their return to the nearest landing facility. However, this may not be a life and death situation, and the pilots may report it as say a "2, yellow, communicate." However, in a similar circumstance, where the engine failure was uncontained, and shrapnel punctured the cabin and wing sections of the aircraft, the crew may declare an emergency because of the engine failure but now report it as " 3 , red, standby." As the crew gets the situation under control, they may update their USER score and report, "2, yellow, communicate." USER is designed to be non-monotonic to allow for immediate changes and updates as the situation progresses. The score is dynamic and can change in seconds. 


\section{Practical Applications}

The applications for USER are multifaceted and applicable to any highconsequence industry that handles stressful and emergency situations. Medical, aviation, space, law enforcement, and firefighting are all examples of industries that could benefit from a universal rating system. Consider the previous aviation example from the introduction. A student pilot ventures into an area of decreasing weather conditions with poor visibility. The student pilot calls air traffic control to declare an emergency and obtain help. For the air traffic controller receiving that emergency call, (s)he is unaware of the current situation, the pilot's skill level, the pilot's ability to handle the emergency, or the overall level of stress that the pilot is under. With the USER score, the pilot may immediately convey this information to the air traffic controller. The pilot could tell air traffic control (s)he is declaring an emergency, "two, yellow, communicate." The controller now knows the pilot is declaring an emergency, but they also know that the severity level is in the mid-range, the pilot may need help, and the pilot is willing/able to communicate with the controller.

\section{Future Research}

There are many areas of future research potential for USER. The first step would be to conduct a behavioral analysis of the model using air traffic controllers and pilots. In the study, pilots would encounter simulated emergency scenarios, and then work to convey this information to air traffic controllers. The experimental trials could test USER against the current means of communication. Additionally, data could be collected on the usability of the reporting model by the air traffic controllers and pilots to examine how USER may help provide a context in emergency situations.

Any high consequence industry where communication needs to occur between multiple parties could benefit from USER. For example, applications could expand into the medical, space, firefighting, and law enforcement fields.

\section{VFR into IMC Scenario: USER Applied}

The quiet of the night was broken by a mayday call that came through the controller's headset on the emergency guard frequency. A VFR pilot practicing night landings at a local non-towered airport had become disorientated in deteriorating weather conditions, and the pilot was unable to maintain visual conditions: 
PILOT: MAYDAY, MAYDAY, MAYDAY, 3, red, communicate, I'm a VFR pilot, and I have flown into IMC.

The controller now knows much more context of the situation than in the first example. They know that the pilot is calling with an emergency, it is very severe (from the pilots' perspective, it is the most serious type of emergency), the pilot needs help, and (s)he want the controller to talk to him or her.

ATC: Roger, N1234. What I want you to focus on first is maintaining a level attitude by looking at the attitude indicator.

The controller checks at the air traffic control facility and identifies a controller who also has their current pilot's license and brings them over to their control station.

ATC: N1234, good job maintaining a level attitude, we have another controller here who is a pilot that is going to talk to you.

PILOT: N1234, roger, go ahead.

ATC: N1234, what is your USER score now?

PILOT: N1234, 3, red, communicate.

ATC: N1234, roger, you're doing a good job holding your wings level. I'd like you to use your attitude indicator and heading indicator to fly a heading of 280. Make sure you watch the attitude indicator and heading, and don't make too steep of a turn. Since you're in the clouds, it is important that you trust your instruments and not your sensations.

The controllers watch on the radar screen as the pilots reposition the aircraft to a 280 heading.

ATC: N1234, it looks like you're on a 280 heading now, keep your wings level and fly that heading. It will take you toward VFR conditions. What's your USER score?

PILOT: N1234, 2, yellow, communicate.

Here that the USER score is now being used dynamically. The sender can update the USER score to inform the recipient that the situation has changed and that the severity level has decreased, while the pilot's capability level has increased. This allows the recipient to instantly recognize that the communication is working and that the pilot is no longer in panic mode.

ATC: N1234, roger, it looks like you'll start encountering VFR conditions soon. 
PILOT: N1234, I'm starting to make ground contact, I've come out of the clouds, 1, white, communicate.

ATC: N1234, we're glad to hear that, say intentions.

From this exchange, the USER model was able to provide the controllers with much more information on the current state the pilot was operating in under the emergency condition. Based on this information, the controller leveraged resources to help the pilot, which may have taken much longer to identify without the use of an expedited model such as USER. Furthermore, the USER score was used in a dynamic fashion to enable the pilot to update ATC on the severity and capabilities during the situation. In emergency situations, time is often critical and as was seen in the first example, there was not enough time for the controller to acquire additional information to identify the resources that were needed by the pilot.

\section{Conclusions}

The purpose of the USER score is to provide an enhanced, and dynamic, method of communication under high stress and high consequence emergency situations. The model proposes to convey three important pieces of information from the sender to the receiver: severity of the situation, capabilities of the sender, and communication ability. The sender rates the severity of the emergency on a scale from minor (1) to moderate (2) to severe (3). They state their capabilities of handling the emergency through color-coding. White does not require help, yellow may need help, and red requires help. Finally, the USER model provides information on whether the individual can communicate or if they need time to process the situation. The USER score is designed to be non-monotonic, and it can change quickly as the scenario progresses. USER has the potential to be applied in some high consequence industries that require the rapid, clear and concise transmission of information. The next step in the development of this conceptual model needs to focus on experimental studies, and future research is required to examine the effectiveness of this proposed model of communication. 


\section{References}

Aircraft Owner's and Pilot's Association (AOPA). (2016). 25 ${ }^{\text {th }}$ Joseph T. Nall report: General aviation accidents in 2013. Retrieved from: https://www.aopa.org/-/media/files/aopa/home/training-and-safety/nallreport/25thnallreport.pdf

Connell, L. (1996). Pilot and controller communication issues. In B. G. Kanki \& V. O. Prinzo (Eds.), Methods and metrics of voice communication (pp. 1927). Washington, DC: US Federal Aviation Administration.

Cushing, S. (1994). Fatal words: Communication clashes and aircraft crashes. Chicago, IL: University of Chicago Press

Drury, C. G., \& Ma, J. (2002). Language error analysis - Report on literature of aviation language errors and analysis of error databases. Report prepared for the Federal Aviation Administration (FAA). University of Buffalo, State University of New York.

Kanki, B. G., \& Palmer, M. T. (1993). Communication and crew resource management. In E. L. Wiener, B. G. Kanki, \& R. L. Helmreich (Eds.) Cockpit resource management (pp. 99-135). San Diego, CA: Academic Press.

Knapp, M. L., Hall, J. A., \& Horgan, T, G, (2012). Nonverbal communication in human interaction. Boston, MA: Wadsworth, Cengage Learning.

MacBurnie, E. (2004). Aviation language proficiency. ICAO Journal, 59(1), 4-27

National Transportation Safety Board (1989). Safety report: General aviation accidents involving visual flight rules flight into instrument meteorological conditions (NTSB/SR-89/01). Washington, DC: Author.

O’Hare, D. \& Smitheram, T. (1995). "Pressing on" into deteriorating weather conditions: An application of behavioral decision theory to pilot decision making. The International Journal of Aviation Psychology, 5, 351-370.

Russell, J.A. \& Fernandez-Dols, J.M. (1997). The psychology of facial expression. Cambridge, MA: Cambridge Press. 
Wiegmann, D. A., \& Goh, J. (2000). Visual flight rules (VFR) flight into adverse weather: An empirical investigation of factors affecting pilot decision making (Technical Report ARL-00-15/FAA-00-8). Savoy, IL: University of Illinois, Aviation Research Lab 